\title{
BMJ open Grip strength and lower limb extension power in 19-72-year-old Danish men and women: the Health2006 study
}

\author{
Mette Aadahl, ${ }^{1}$ Nina Beyer, ${ }^{2}$ Allan Linneberg, ${ }^{1}$ Betina Heinsbæk Thuesen, ${ }^{1}$ \\ Torben Jørgensen ${ }^{1,3}$
}

To cite: Aadahl M, Beyer N, Linneberg $A$, et al. Grip strength and lower limb extension power in 19-72-year-old Danish men and women: the Health2006 study. BMJ Open 2011;1: e000192. doi:10.1136/ bmjopen-2011-000192

- Prepublication history for this paper is available online. To view these files please visit the journal online (http:// bmjopen.bmj.com).

Received 26 May 2011 Accepted 5 August 2011

This final article is available for use under the terms of the Creative Commons Attribution Non-Commercial 2.0 Licence; see http://bmjopen.bmj.com

\begin{abstract}
${ }^{1}$ Research Centre for Prevention and Health, Capital Region of Denmark, Glostrup, Denmark

${ }^{2}$ Musculoskeletal

Rehabilitation Research Unit, Department of Physical Therapy, Bispebjerg Hospital, Copenhagen, Denmark ${ }^{3}$ Faculty of Health Sciences, University of Copenhagen, Copenhagen, Denmark
\end{abstract}

Correspondence to Dr Mette Aadahl; metaad01@glo.regionh.dk

\section{ABSTRACT}

Aim: To assess muscular fitness by hand grip strength (HGS) and lower limb extension power (LEP) and to explore associations with age, leisure time physical activity (LTPA) and body composition.

Study population: A population-based sample of 19-72-year-old men and women were invited to participate in the health survey 'Health2006'. The response rate was $43.8 \%(\mathrm{~N}=3471), 55 \%$ were women, and the mean age was $49 \pm 13$ years.

Methods: Height, weight, waist circumference, HGS and LEP were measured and participants answered a self-administered questionnaire. LEP was measured in a subsample of subjects $(n=438)$. Gender-stratified multiple linear regression analyses were carried out. Data were adjusted for age, height and waist circumference.

Results: A large inter-individual variation was found in HGS and LEP. Both measures declined with age and were highly correlated $(r=0.75, p<0.0001)$. LTPA was positively associated with HGS in men $(p=0.0002)$ and women $(p<0.0001)$ in the total sample, but in the subsample was significant in men only $(p=0.004)$; the association between LTPA and LEP was significant in women only $(p=0.02)$.

Conclusion: In this large population-based study sample, muscular fitness declined with age and LTPA was associated with HGS in both genders. The findings emphasise the importance of maintaining a physically active lifestyle at any age.

\section{INTRODUCTION}

In addition to being an active tissue that metabolises lipids, stores ingested glucose and significantly contributes to basal metabolic rate, skeletal muscle plays an obvious role in locomotion. ${ }^{1}$ Accordingly, muscular fitness has been defined as "muscular strength and power and other properties of muscle that contribute to its mass and quality". ${ }^{1}$ Maximal hand grip strength (HGS) has been described as the simplest method for assessing general muscle strength and function. ${ }^{2}$ It is a strong and consistent predictor of morbidity and mortality in

\section{ARTICLE SUMMARY}

\section{Article focus}

- The present study describes muscular fitness by means of hand grip strength (HGS) and lower limb extension power (LEP) in a large populationbased sample of 19-72-year-old men and women.

- The study explores the associations of HGS and LEP, respectively, with age, leisure time physical activity level and body composition.

\section{Key messages}

- HGS is often measured in large study samples; the present study demonstrates that LEP can also be measured in large population-based study samples.

- HGS and LEP declined with age as expected.

- Leisure time physical activity level was associated with HGS in both genders, but with LEP in women only.

Strengths and limitations of this study

- Strengths of the study include the large population-based study sample of adult men and women and the standardised measurement of muscle strength and power.

- Major limitations are the relatively low response rate that may affect the generalisability of results and the fact that LEP was only measured in a subsample of participants.

middle aged and elderly subjects ${ }^{3-5}$ and of disability in older populations. ${ }^{6}{ }^{7}$ Skeletal muscle function is additionally regarded as a useful indicator of malnutrition, and measurement of HGS has been used as a screening tool for nutritional risk at hospital admission. ${ }^{8}$ Muscle power is the product of force generated and speed of movement, and has been described as the ability of the neuromuscular system to produce the greatest possible force as fast as possible. ${ }^{9}$ Muscle power is an understudied area in population-based studies, although it is required in the movements of sport, work and daily living and has been viewed as a very 
important testing variable. ${ }^{10}$ In sports muscle power may be more related to functional performance than muscle strength, ${ }^{11}$ and improvement in muscle power is important for enhancing athletic performance. ${ }^{12}$ In middle aged and older individuals, the decline in muscle power is approximately twice as great as the decline in isometric strength, ${ }^{13}{ }^{14}$ primarily because the loss of force is magnified by the decline in velocity due to the selective loss of type II fibres. Reduced muscle power is related to mobility limitation and decreased functional performance $^{15-17}$ and the relationship appears to be stronger than the relationship between functional performance and muscle strength. ${ }^{16}{ }^{17}$ In addition, muscle power is related to balance ${ }^{18}$ and lower limb extension power (LEP) has been identified as a predictor of falls in elderly populations over 65 years of age. ${ }^{19}{ }^{20}$ To our knowledge, LEP has not previously been measured in large population samples.

The aim of the present study was to describe muscular fitness, by means of HGS and LEP, in a large populationbased sample of 19-72-year-old Danish men and women and to explore the associations of HGS and LEP, respectively, with age, leisure time physical activity level (LTPA) and body composition.

\section{METHODS}

\section{Study population}

Health2006, a population-based cross-sectional study, was initiated at the Research Centre for Prevention and Health (RCPH) in June 2006 and ended in May 2008. ${ }^{21}$ Participants were recruited through the Danish Civil Registration office as a random sample of men and women between 19 and 72 years of age and living in 11 municipalities in the western area of the Capital Region of Denmark. Pregnant women were not included. Of 7931 men and women invited, 3471 choose to participate, corresponding to a response rate of $43.8 \%$. All participants gave written informed consent before taking part in the study and the study was approved by the local ethics committee (KA20060011).

\section{Physical measurements}

Participants visited the RCPH and underwent an extensive health examination, which has been described in detail elsewhere, ${ }^{22}$ including measurement of height, weight and waist circumference. Height was measured without shoes to the nearest centimetre, weight was measured in light clothing without shoes to the nearest $0.1 \mathrm{~kg}$ and body mass index (BMI) was calculated as $\mathrm{kg} / \mathrm{m}^{2}$. Waist circumference was measured midway between the lower rib margin and the iliac crest to the nearest centimetre, without any pressure on the skin and with an unstretched tape measure.

Muscular fitness was assessed by two different measures of muscle performance in the upper and the lower extremity, respectively. HGS was measured in the dominant hand using a Jamar dynamometer ${ }^{23}$ (Sammons Preston Rolyan, Chicago, Illinois, USA) and following a standardised protocol. The participant was seated in the upright position with the arm along the side; the arm was bent at $90^{\circ}$ at the elbow and the forearm and wrist were in the neutral position. The width of the handle was adjusted to fit the hand size. HGS was measured three times in the dominant hand with brief pauses between each measurement and the best of three measurements was considered the maximum HGS. High inter-rater and test-retest reliability have previously been demonstrated for these standardised measurement procedures. ${ }^{24}$

Maximum single LEP was measured using a Nottingham Leg Extensor Power Rig ${ }^{25}$ (Medical Engineering Unit, University of Nottingham Medical School, Nottingham, UK) as previously described. ${ }^{13}$ The subjects were in a seated position and a single explosive lower limb extension accelerated a flywheel from rest. The maximum speed of the flywheel was used to calculate the average power of the lower limb extensor muscles. The subjects familiarised themselves with the procedure in two warm-up trials followed by a minimum of five and a maximum of 10 maximal trials with approximately $30 \mathrm{~s}$ pause between them. Participants were given verbal

Table 1 Sociodemographic characteristics, muscle performance, body composition, physical activity level and functional limitation among men and women in the Health2006 study population $(\mathrm{N}=3471)$

\begin{tabular}{|c|c|c|}
\hline Variable & $\begin{array}{l}\text { Men } \\
(\mathrm{N}=1553) \\
\text { mean (SD) }\end{array}$ & $\begin{array}{l}\text { Women } \\
(N=1918), \\
\text { mean (SD) }\end{array}$ \\
\hline Age, years & $50(13)$ & 49 (13) \\
\hline Grip strength, kg & $49.2(8.0)$ & $31.1(6.1)$ \\
\hline $\begin{array}{l}\text { Lower limb extension } \\
\text { power, Watt* }\end{array}$ & $286(92)$ & $160(56)$ \\
\hline $\mathrm{BMI}, \mathrm{kg} / \mathrm{m}^{2}$ & $26.5(4.1)$ & $25.4(5.1)$ \\
\hline Waist circumference, $\mathrm{cm}$ & $95(12)$ & $83(13)$ \\
\hline \multirow[t]{2}{*}{ Height, cm } & $179(6.8)$ & $166(6.4)$ \\
\hline & N (\%) & N (\%) \\
\hline \multicolumn{3}{|l|}{ Physical activity (leisure) } \\
\hline Sedentary & $283(18)$ & $354(18)$ \\
\hline Moderate activity & $873(57)$ & $1212(64)$ \\
\hline High/vigorous activity & $378(25)$ & $340(18)$ \\
\hline \multicolumn{3}{|l|}{ School education $\dagger$} \\
\hline$\leq 7$ years & $171(11)$ & $122(6)$ \\
\hline $8-9$ years & $316(21)$ & $304(16)$ \\
\hline 10 years & $437(28)$ & $582(31)$ \\
\hline$>10$ years & $484(32)$ & $668(36)$ \\
\hline \multicolumn{3}{|l|}{ Employment status } \\
\hline Employed & $1162(76)$ & $1358(72)$ \\
\hline Formerly employed & $341(22)$ & $499(26)$ \\
\hline Never employed & $26(2)$ & $30(2)$ \\
\hline \multicolumn{3}{|l|}{ Limited in stair-climbing } \\
\hline Yes, very limited & $32(2)$ & $50(3)$ \\
\hline Yes, slightly limited & $174(11)$ & $344(18)$ \\
\hline No & $1321(87)$ & $1497(79)$ \\
\hline
\end{tabular}

*Lower limb extension power data from 438 participants only (183 men and 255 women).

tInformation on school education was missing for 19 men and 33 women, and $126(8 \%)$ men and 209 (11\%) women reported 'other' school education. 
encouragement during measurements in order to ensure full activation and generation of maximal muscle power. The right lower limb was measured, unless the participant had a knee or ankle problem in the right lower limb, in which case the left lower limb was measured. High test-retest reliability of the LEP measurement has been reported using the Nottingham Leg Extensor Power Rig and following the standardised measurement protocol. ${ }^{25}$

All measurements were carried out by the same four trained nurses and laboratory technicians.

\section{Questionnaire}

Information on sociodemographic variables, physical activity and functional limitation was measured by a selfreport questionnaire. Participants were asked to categorise their usual physical activity level during leisure time as one of the following: (1) mainly sedentary, (2) lightly active, (3) moderately active or (4) vigorously active. ${ }^{26}$ Categories 3 and 4 were combined for the analyses as there were few participants in category 4. Functional limitation was defined as being limited in climbing several flights of stairs because of one's health: (very limited, slightly limited, not limited). ${ }^{27}$ Education was determined as the number of years of school education completed ( $\leq 7$ years, $8-9$ years, 10 years or $>10$ years) and employment status was assessed in three categories (currently employed, formerly employed, never employed).
Statistical analysis

Baseline characteristics were calculated for men and women separately and are presented as means $( \pm \mathrm{SD})$ and percentages unless otherwise stated. Data from men and women were analysed separately throughout, but we used tests for interactions to compare gender differences formally. Pearson's correlation coefficient was used to determine the correlation between HGS and LEP.

Univariate associations between age group and HGS and LEP, respectively, were assessed in general linear regression models. Likewise, we explored the association of HGS and LEP, respectively, with height, waist circumference and LTPA in general linear regression analyses adjusting for age. We determined regression coefficients and regression lines of the association between age and HGS and LEP, respectively, in a linear regression model. Finally, the associations between LTPA and muscular fitness were estimated in multiple linear regression models with HGS and LEP, respectively, as outcome variables and LTPA as the primary explanatory variable. Age, height and waist circumference were included as covariates and were entered as continuous variables. Age and waist were entered in a quadratic form, while height was entered in a linear form. Least squares (LS) means were estimated from the regression models with a mean estimate for age, height and waist circumference for men and women separately. We used $\mathrm{F}$ tests to test for interaction between age and LTPA level in all models,

Table 2 Mean handgrip strength in men and women of different age groups, leisure time physical activity level and body composition $(\mathrm{N}=3471)$

\begin{tabular}{|c|c|c|c|c|}
\hline \multirow[b]{3}{*}{ Variable } & \multicolumn{4}{|c|}{ Handgrip strength (kg) } \\
\hline & \multicolumn{2}{|l|}{ Men } & \multicolumn{2}{|c|}{ Women } \\
\hline & $\mathbf{N}$ & Mean (SD) & $\mathbf{N}$ & Mean (SD) \\
\hline \multicolumn{5}{|l|}{ Age group } \\
\hline $19-29$ years & 104 & $50.5(8.2)$ & 183 & $32.4(5.1)$ \\
\hline $30-39$ years & 218 & $52.7(7.7)$ & 280 & $34.4(5.8)$ \\
\hline $40-49$ years & 382 & $52.9(7.1)$ & 486 & $33.7(5.4)$ \\
\hline $50-59$ years & 383 & $48.9(7.0)$ & 476 & $30.2(5.5)$ \\
\hline \multirow[t]{2}{*}{$60-72$ years } & 461 & $44.4(6.8)$ & 480 & $26.7(4.8)$ \\
\hline & & $p<0.0001$ & & $\mathrm{p}<0.0001$ \\
\hline \multicolumn{5}{|l|}{ Height } \\
\hline Women $<160 /$ men $<175 \mathrm{~cm}$ & 423 & $44.6(6.9)$ & 327 & $27.6(5.2)$ \\
\hline Women $160-164 /$ men $175-179 \mathrm{~cm}$ & 368 & $48.3(7.0)$ & 427 & $29.7(5.4)$ \\
\hline Women $165-170 /$ men $180-185 \mathrm{~cm}$ & 447 & $51.5(7.4)$ & 620 & $31.8(6.0)$ \\
\hline \multirow{2}{*}{ Women $>170 /$ men $>185 \mathrm{~cm}$} & 269 & $53.3(7.9)$ & 463 & $33.8(6.0)$ \\
\hline & & $\mathrm{p}<0.0001^{*}$ & & $\mathrm{p}>0.0001^{*}$ \\
\hline \multicolumn{5}{|l|}{ Waist circumference } \\
\hline Normal (women <80/men <94 cm) & 740 & $49.4(7.7)$ & 850 & $31.4(5.7)$ \\
\hline Overweight (women 80-88/men 94-102 cm) & 547 & $49.4(8.1)$ & 490 & $30.7(6.3)$ \\
\hline \multirow[t]{2}{*}{ Obese $($ women $>88 /$ men $>102 \mathrm{~cm}$ ) } & 349 & $48.6(8.3)$ & 577 & $30.9(6.4)$ \\
\hline & & $\mathrm{p}=0.005^{\star}$ & & $\mathrm{p}=0.01^{\star}$ \\
\hline \multicolumn{5}{|l|}{ Physical activity level (leisure time) } \\
\hline Sedentary & 281 & $48.4(8.2)$ & 347 & $30.6(6.1)$ \\
\hline Moderate activity & 870 & $49.0(7.9)$ & 1203 & $30.9(6.0)$ \\
\hline \multirow[t]{2}{*}{ High/vigorous activity } & 377 & $50.3(7.7)$ & 337 & $32.3(6.0)$ \\
\hline & & $\mathrm{p}=0.0007^{*}$ & & $\mathrm{p}=0.0001^{*}$ \\
\hline
\end{tabular}


Table 3 Mean lower limb extension power in men and women of different age groups, leisure time physical activity level and body composition $(\mathrm{N}=438)$

\begin{tabular}{|c|c|c|c|c|}
\hline \multirow[b]{3}{*}{ Variable } & \multicolumn{4}{|c|}{ Lower limb extension power (Watts) } \\
\hline & \multicolumn{2}{|l|}{ Men } & \multicolumn{2}{|c|}{ Women } \\
\hline & $\mathbf{N}$ & Mean (SD) & $\mathbf{N}$ & Mean (SD) \\
\hline \multicolumn{5}{|l|}{ Age group } \\
\hline $19-29$ years & 16 & $340(95)$ & 25 & $193(48)$ \\
\hline $30-39$ years & 20 & $309(90)$ & 40 & $183(66)$ \\
\hline $40-49$ years & 45 & $342(93)$ & 54 & $184(45)$ \\
\hline $50-59$ years & 35 & $274(68)$ & 71 & $155(50)$ \\
\hline \multirow[t]{2}{*}{$60-72$ years } & 67 & $234(73)$ & 65 & $119(41)$ \\
\hline & & $\mathrm{p}<0.0001$ & & $\mathrm{p}<0.0001$ \\
\hline \multicolumn{5}{|l|}{ Height } \\
\hline Women $<160 /$ men $<175 \mathrm{~cm}$ & 40 & $237(72)$ & 41 & $135(50)$ \\
\hline Women $160-164 /$ men $175-179 \mathrm{~cm}$ & 49 & $272(53)$ & 53 & $143(50)$ \\
\hline Women $165-170 /$ men $180-185 \mathrm{~cm}$ & 51 & $310(88)$ & 88 & $163(53)$ \\
\hline \multirow[t]{2}{*}{ Women $>170 /$ men $>185 \mathrm{~cm}$} & 39 & $324(99)$ & 55 & $192(59)$ \\
\hline & & $\mathrm{p}=0.018^{*}$ & & $\mathrm{p}<0.0001^{*}$ \\
\hline \multicolumn{5}{|l|}{ Waist circumference } \\
\hline Normal (women <80/men <94 cm) & 83 & $276(89)$ & 109 & $151(51)$ \\
\hline Overweight (women 80-88/men 94-102) & 58 & $302(88)$ & 59 & $169(55)$ \\
\hline \multirow[t]{2}{*}{ Obese (women >88/men >102) } & 46 & $283(102)$ & 87 & $166(62)$ \\
\hline & & $p=0.0002^{*}$ & & $\mathrm{p}<0.0001^{*}$ \\
\hline \multicolumn{5}{|l|}{ Physical activity level (leisure time) } \\
\hline Sedentary & 33 & $292(108)$ & 52 & $148(57)$ \\
\hline Moderate activity & 107 & $284(94)$ & 157 & $160(56)$ \\
\hline \multirow[t]{2}{*}{ High/vigorous activity } & 41 & $286(75)$ & 44 & $172(55)$ \\
\hline & & $p=0.76^{*}$ & & $\mathrm{p}=0.25^{\star}$ \\
\hline
\end{tabular}

in order to explore whether age-related decline in muscle strength and power differed by level of LTPA. All statistical analyses were performed using SAS V.9.2.

\section{RESULTS}

Among participants, $55 \%$ were women $(n=1918)$ and the mean age was $49.4 \pm 13$ years (median 50, range 19-72). The characteristics of the study population are presented in table 1 . There were significantly more men among non-responders $(54 \%$ men among non-

A

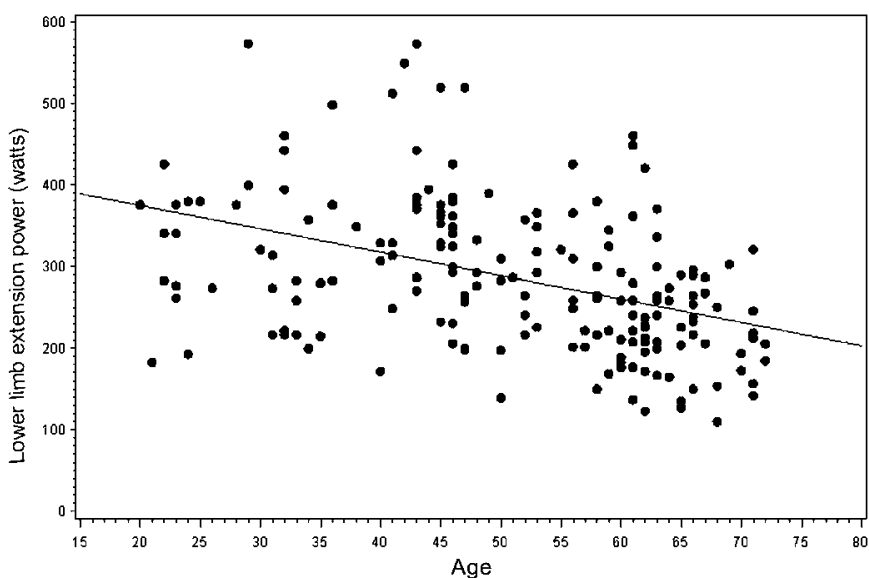

responders vs $45 \%$ men among participants, $\mathrm{p}<0.001)$ and non-responders were markedly younger than participants (mean age $45.7 \pm 15$ years, $\mathrm{p}<0.001$ ). Overall, non-response was inversely correlated with age and, particularly in the youngest age group, the participation rate was very low.

In the entire study population, $10 \%$ of participants $(n=331)$ were left-handed. The mean HGS in men and women across groups of different ages, heights, waist circumference and LTPA levels is presented in table 2.
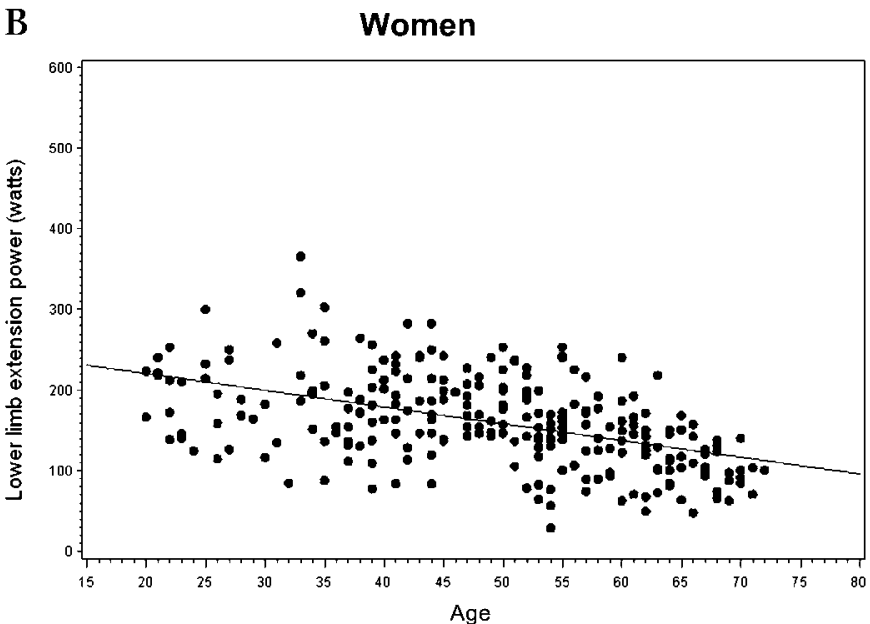

Figure 1 Lower limb extension power (Watts) plotted against age in men $(n=183)$ and women $(n=255)$. Regression lines: $\mathrm{y}=-2.8581$ (age) +431.47 and $\mathrm{y}=-2.0936$ (age) +262.93 in men and women, respectively. 
A

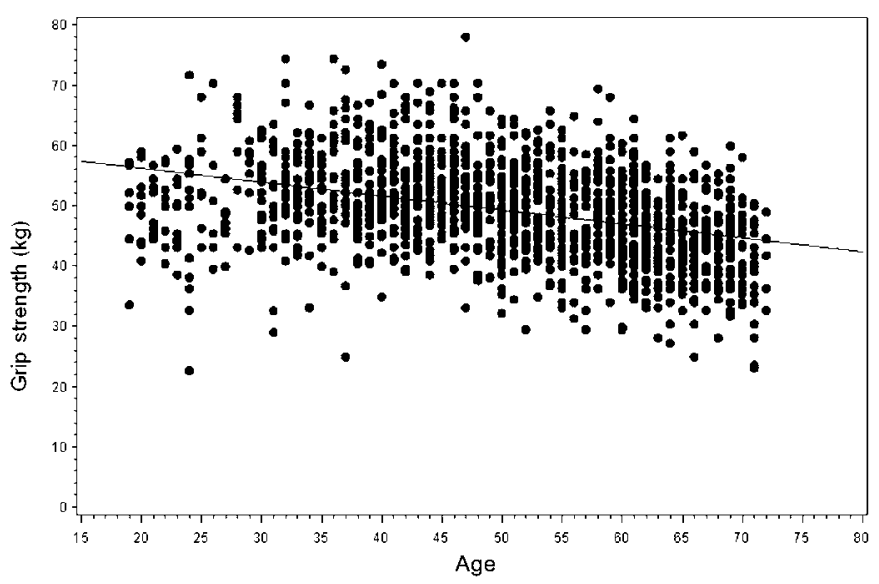

B

Women

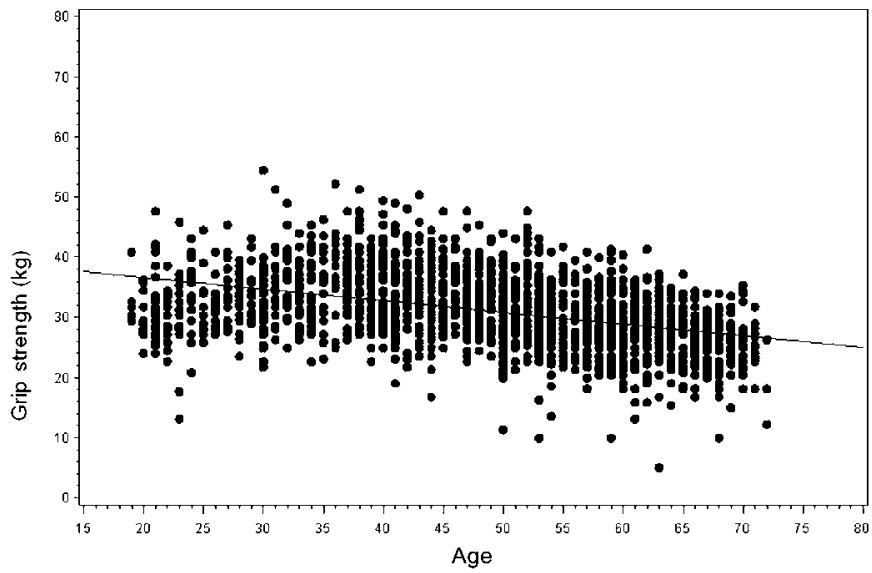

Figure 2 Hand grip strength $(\mathrm{kg})$ plotted against age in men $(n=1548)$ and women $(n=1905)$. Regression lines: $y=-0.2318(a g e)$ +60.814 and $\mathrm{y}=-0.1934(\mathrm{age})+40.471$ in men and women, respectively.

Grip strength varied according to age and gender as expected. Maximum strength was observed in midlife (40-49 years of age in men and 30-39 years of age in women) and thereafter decreased with increasing age in both genders (table 2). HGS increased with increasing height, whereas there was a significant inverse relationship between HGS and waist circumference in both genders. Finally, physical activity level was positively associated with HGS in both genders.

LEP was measured during the last months of the Health2006 study and hence LEP is only available in a subgroup of 438 participants (183 men and 255 women). Only three of the 438 participants performed the test with the left lower limb. Mean LEP in men and women across groups of different ages, heights, waist circumference and LTPA levels is presented in table 3. LEP decreased with increasing age (table 3). A large inter-individual variation in HGS and LEP was seen in all age groups. LEP increased with increasing height and, unlike HGS, was significantly higher in overweight and obese men and women than in participants of normal weight, as defined by waist circumference. Finally, phys-

A

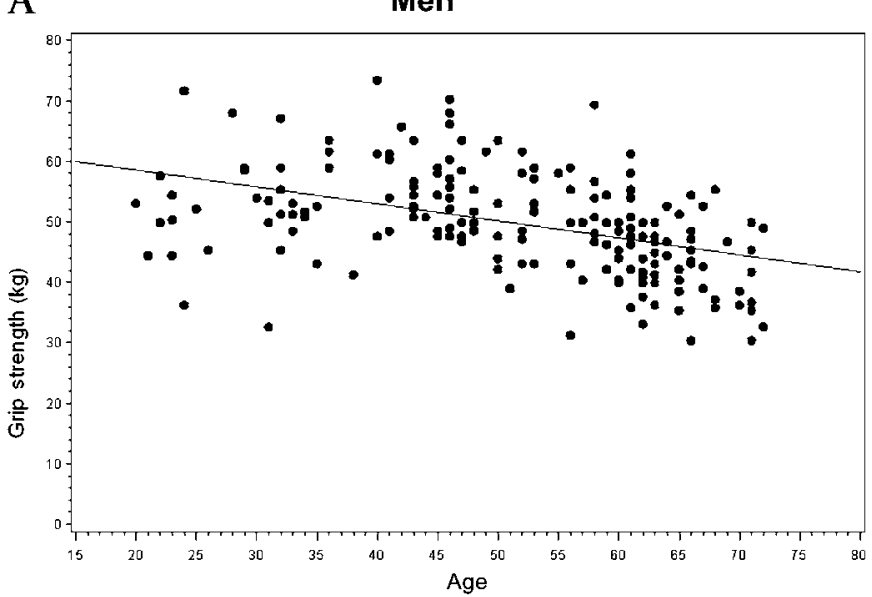

ical activity level was not associated with LEP in these age-adjusted analyses (table 3 ).

In figure 1 the LEP values are plotted against age and regression lines show the age-related decline in LEP in men and women, respectively. Similarly, HGS is regressed against age in figures 2 and 3. Overall, LEP and HGS were significantly correlated $(r=0.75$, $\mathrm{p}<0.0001$ ) (data not shown).

When adjusted for age, height and waist circumference, LTPA was significantly associated with HGS in men $(\mathrm{p}=0.0002)$ and women $(\mathrm{p}<0.0001)$ (data not shown). However, in the subsample where both HGS and LEP measurements were available, LTPA was significantly associated with HGS in men only (figure 4), whereas LTPA was significantly associated with LEP in women only (figure 5). No significant interaction between age and LTPA was found in the analysis with HGS or with LEP.

\section{DISCUSSION}

The present population-based study of 19-72-year-old Danish men and women demonstrates that both HGS and LEP decreased with age as expected. The

B

Women

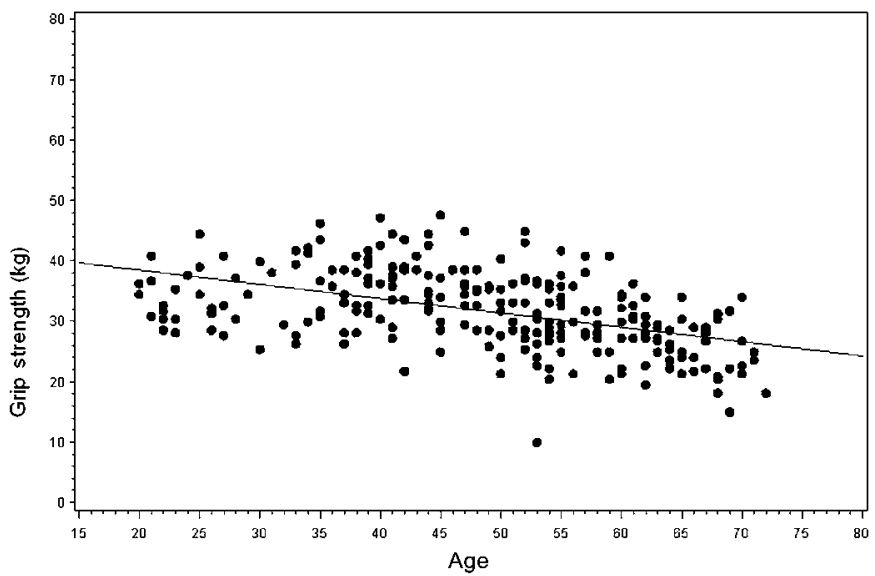

Figure 3 Hand grip strength $(\mathrm{kg})$ plotted against age in men $(n=183)$ and women $(n=255)$. Regression lines: $y=-0.2795($ age $)$ +64.117 and $y=-0.2363$ (age)+43.218 in men and women, respectively. 
Figure 4 Handgrip strength in men and women, respectively, across categories of leisure time physical activity, presented as least squares (LS) means with 95\% Cls. LS means are estimated in a linear regression model with a mean estimate for age, height and waist circumference. $p$ Value for the association between leisure time physical activity level and handgrip strength, adjusted for age, height and waist circumference.

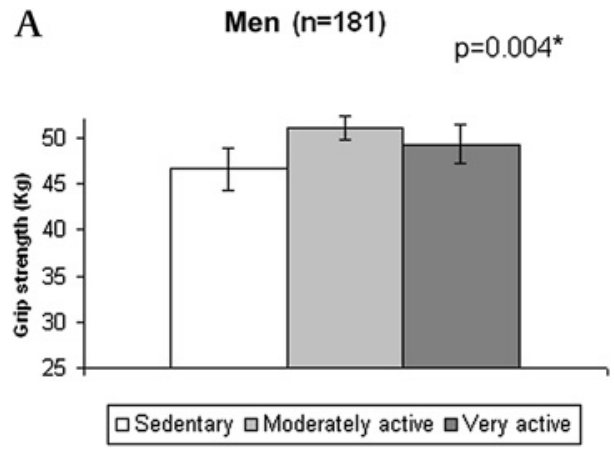

relationship between age and LEP in this study corresponds very well with previous findings in small volunteer study samples of men and women ${ }^{25}$ and in nontrained healthy men. ${ }^{14}$ Scatter plots and regression lines illustrating the age-related decline in LEP are remarkably similar, considering the difference in study populations.

Grip strength reference values vary significantly among different populations and with the type of hand grip dynamometer used. ${ }^{28}$ However, the reported HGS values and the age-related decline after 45 years of age correspond well with findings in a longitudinal study of Danish men and women over 45 years of age, although a Smedley dynamometer was used. ${ }^{29}$ Interestingly, Frederiksen et al found that the decline reached a horizontal plateau in the oldest women $(90+$ years $)$ when adjustment was made for selective drop-out of the weakest participants. ${ }^{29}$ The oldest participants in our study were 72 years of age and, accordingly, we did not observe a similar horizontal plateau.

We found that waist circumference was negatively associated with HGS in both genders, whereas it was positively associated with LEP. This difference may be explained by the fact that a large body, whether fat or muscle, demands great strength and power of the lower extremities when moving about, whereas a large waist circumference does not necessarily require great strength of the upper extremities.

In the present study, HGS was significantly associated with physical activity in both men and women in the entire study sample. Previous studies in large popula- tions of older and middle aged subjects have similarly documented that HGS is associated with physical activity, ${ }^{29} 30$ which in itself predicts better survival, less disability and less morbidity.

In the subsample, HGS was significantly associated with physical activity in men only, while the association between physical activity level and LEP was significant in women only. However, LEP was only measured in a relatively small subsample and results should therefore be interpreted cautiously. The findings could be due to the great variation in HGS and LEP (figures 1, 2 and 3) and thus lack of statistical power. Moreover, LTPA was selfreported and rather crude and we were unable to distinguish between different kinds of LTPA. Certain types of physical activity may primarily involve lower limb power, for example, running or cycling, whereas arm and HGS may be involved in other types of activity, for example, tennis or badminton. Likewise, different occupations may require specific types of muscle work in the upper or the lower extremities. However, we did not have detailed information on participants' occupation to explore this in the analyses.

Frederiksen et al found that genetic effects accounted for $52 \%$ of the variation in HGS and the genetic effect was constant across age groups. ${ }^{30}$ Likewise, results from twin studies suggest that one-third to one-half of the individual variation in LEP among older people is accounted for by genetic effects. ${ }^{31}$ This suggests that muscle strength and power may be the result of interactions between environmental and genetic effects. 90 Recently, birth cohort studies have reported strong
Figure 5 Lower limb extension power in men and women, respectively, across categories of leisure time physical activity, presented as least squares (LS) means with $95 \%$ Cls. LS means are estimated in a linear regression model with a mean estimate for age, height and waist circumference. $p$ Value for the association between leisure time physical activity level and handgrip strength, adjusted for age, height and waist circumference.
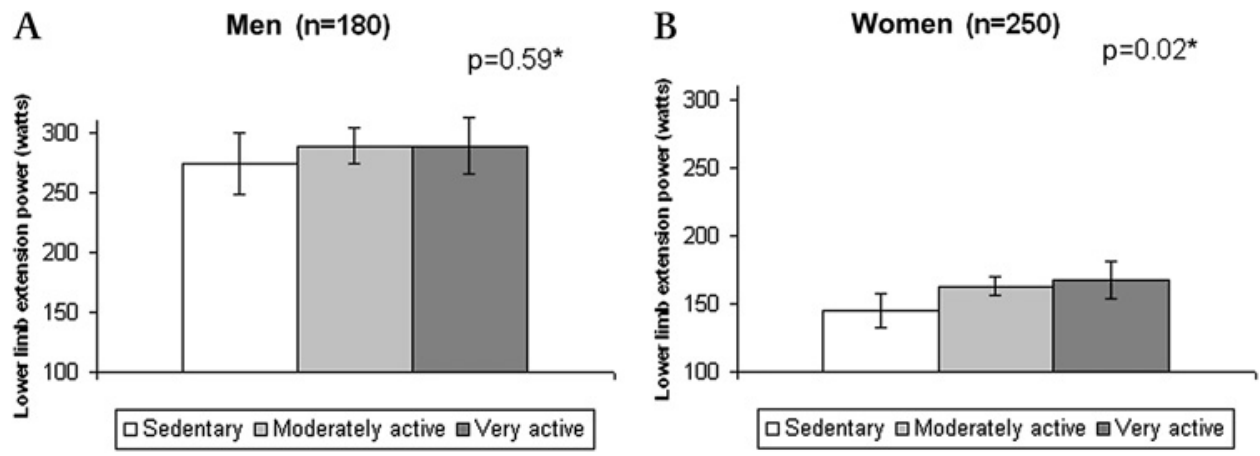
associations between birth weight and HGS in midlife, suggesting that environmental influences during gestation may also affect adult grip strength, ${ }^{32} 33$ possibly through the number of muscle fibres established at birth. As a result, some people may have poorer 'starting values' and thus be at increased risk for muscle impairment or sarcopenia, but behaviour, in particular physical activity, also has a key role in maintaining muscle performance at an adequate level, especially in old age. ${ }^{34}$ This emphasises the importance of maintaining a physically active lifestyle at any age throughout life.

It seems worth noting that, overall, HGS and LEP were highly correlated in the present study. This supports the use of HGS as a single, simple and inexpensive method for assessing general muscle strength and function. ${ }^{2}$

The present study has several strengths and limitations that should be mentioned. Strengths include the large population-based sample of adult men and women and the measurement of HGS and LEP in the same study. The standardised measurement of muscle strength and power performed by the same four trained nurses and laboratory technicians is also a strength of the present study. A major limitation of our study is the relatively low response rate that may affect the generalisability of results; the response rate was low especially in the younger age groups. However, the age and gender distribution of HGS and LEP values correspond very well with findings from other studies. We consider this an indication that our results have not been severely biased by the low participation rate. Finally, the crosssectional design of our study does not allow for causal inferences regarding the association between physical activity and HGS or LEP, or on the relationship with age.

In conclusion, we found that HGS and LEP declined with age in both genders and that LTPA was associated with HGS in both genders, but with LEP in women only. Studies on LEP in larger study populations are needed in order to obtain reference values which the present study does not have sufficient data to provide. Larger study samples and reference values are necessary for further exploration of the significance of muscle strength and power in relation to functional capacity, well-being and other health outcomes.

\section{Perspectives}

As demonstrated in the present study, LEP can be measured in population-based studies along with HGS. Increasing research-based evidence suggests that muscle strength and power play an important role not only in sport but also in relation to chronic conditions and disability in older people. Consequently, age-related reference values for muscle strength and power in sedentary and physically active people would be useful. This also emphasises the need for feasible methods for collecting valid data on muscle strength and power in large population-based study samples.
Correction notice The "To cite: ..." information and running footer in this article have been updated with the correct volume number (volume 1).

Funding This work was supported by Timber Merchant Vilhelm Bangs Foundation, The Danish Heart Foundation, The Danish Board of Health, The Danish Environmental Protection Agency, The Copenhagen County Research Foundation, Aase and Einar Danielsens Foundation, The Velux Foundation, ALK-Abelló A/S (Hørsholm, Denmark), The Danish Scientific Research Council, and The Health Insurance Foundation (Helsefonden).

\section{Competing interests None.}

Ethics approval This study was approved by the local ethics committee of Copenhagen county (KA20060011).

Contributors AL, TJ and MAa were responsible for the conception and design of the study. NB provided advice on the methodology of data collection. NB, BT and MAa undertook the analysis and interpretation of data. MAa produced the first draft of the article and NB, BT, AL and TJ critically revised the manuscript. All authors approved the final version of the manuscript.

Provenance and peer review Not commissioned; externally peer reviewed.

Data sharing statement No additional data available.

\section{REFERENCES}

1. McCartney N, Phillips S. Physical activity, muscular fitness, and health. In: Bouchard C, Blair SN, Haskell WL, eds. Physical Activity and Health. Champaign, IL: Human Kinetics, 2007:231-57.

2. Bohannon RW. Is it legitimate to characterize muscle strength using a limited number of measures? J Strength Cond Res 2008;22:166-73.

3. Gale CR, Martyn CN, Cooper C, et al. Grip strength, body composition, and mortality. Int J Epidemiol 2007;36:228-35.

4. Sasaki H, Kasagi F, Yamada M, et al. Grip strength predicts causespecific mortality in middle-aged and elderly persons. Am J Med 2007; 120:337-42.

5. Bohannon RW. Hand-grip dynamometry predicts future outcomes in aging adults. J Geriatr Phys Ther 2008;31:3-10.

6. Rantanen T, Guralnik JM, Foley D, et al. Midlife hand grip strength as a predictor of old age disability. JAMA 1999;281:558-60.

7. Rantanen T. Muscle strength, disability and mortality. Scand J Med Sci Sports 2003;13:3-8.

8. Schlussel MM, dos Anjos LA, de Vasconcellos MT, et al. Reference values of handgrip dynamometry of healthy adults: a populationbased study. Clin Nutr 2008;27:601-7.

9. Tiainen K, Sipila S, Kauppinen M, et al. Genetic and environmental effects on isometric muscle strength and leg extensor power followed up for three years among older female twins. J Appl Physiol 2009;106:1604-10.

10. American College of Sports Medicine. American College of Sports Medicine position stand. Progression models in resistance training for healthy adults. Med Sci Sports Exerc 2009;41:687-708.

11. Requena B, Gonzalez-Badillo JJ, de Villareal ES, et al. Functiona performance, maximal strength, and power characteristics in isometric and dynamic actions of lower extremities in soccer players. $J$ Strength Cond Res 2009;23:1391-401.

12. Frost DM, Cronin J, Newton RU. A biomechanical evaluation of resistance: fundamental concepts for training and sports performance. Sports Med 2010;40:303-26.

13. Skelton DA, Greig CA, Davies JM, et al. Strength, power and related functional ability of healthy people aged 65-89 years. Age Ageing 1994;23:371-7

14. Pearson SJ, Young A, Macaluso A, et al. Muscle function in elite master weightlifters. Med Sci Sports Exerc 2002;34:1199-206.

15. Bean JF, Kiely DK, Herman S, et al. The relationship between leg power and physical performance in mobility-limited older people. J Am Geriatr Soc 2002;50:461-7.

16. Bassey EJ, Fiatarone MA, O'Neill EF, et al. Leg extensor power and functional performance in very old men and women. Clin Sci (Lond) 1992;82:321-7

17. Foldvari M, Clark M, Laviolette LC, et al. Association of muscle powe with functional status in community-dwelling elderly women. J Gerontol A Biol Sci Med Sci 2000;55:M192-9.

18. Orr R. Contribution of muscle weakness to postural instability in the elderly. A systematic review. Eur J Phys Rehabil Med 2010;46:183-220.

19. Perry MC, Carville SF, Smith IC, et al. Strength, power output and symmetry of leg muscles: effect of age and history of falling. Eur $J$ Appl Physiol 2007;100:553-61. 
20. Skelton DA, Kennedy J, Rutherford OM. Explosive power and asymmetry in leg muscle function in frequent fallers and non-fallers aged over 65. Age Ageing 2002;31:119-25.

21. Thyssen JP, Linneberg $A$, Menne $T$, et al. The prevalence and morbidity of sensitization to fragrance mix I in the general population. Br J Dermatol 2009;161:95-101.

22. Hersoug LG, Husemoen LL, Thomsen SF, et al. Association of indoor air pollution with rhinitis symptoms, atopy and nitric oxide levels in exhaled air. Int Arch Allergy Immunol 2010;153:403-12.

23. Mathiowetz V, Kashman N, Volland G, et al. Grip and pinch strength: normative data for adults. Arch Phys Med Rehabil 1985;66:69-72.

24. Roberts $\mathrm{HC}$, Denison HJ, Martin HJ, et al. A review of the measurement of grip strength in clinical and epidemiological studies: towards a standardised approach. Age Ageing 2011;40:423-9.

25. Bassey EJ, Short AH. A new method for measuring power output in a single leg extension: feasibility, reliability and validity. Eur J Appl Physiol Occup Physiol 1990;60:385-90.

26. Saltin B, Grimby G. Physiological analysis of middle-aged and old former athletes. Comparison with still active athletes of the same ages. Circulation 1968:38:1104-15.

27. Ware J Jr, Kosinski M, Keller SD. A 12-Item Short-Form Health Survey: construction of scales and preliminary tests of reliability and validity. Med Care 1996;34:220-33.
28. Jeune B, Skytthe A, Cournil A, et al. Handgrip strength among nonagenarians and centenarians in three European regions. J Gerontol A Biol Sci Med Sci 2006;61:707-12.

29. Frederiksen $\mathrm{H}$, Hjelmborg J, Mortensen $\mathrm{J}$, et al. Age trajectories of grip strength: cross-sectional and longitudinal data among 8,342 Danes aged 46 to 102. Ann Epidemiol 2006;16:554-62.

30. Frederiksen $\mathrm{H}$, Gaist D, Petersen $\mathrm{HC}$, et al. Hand grip strength: a phenotype suitable for identifying genetic variants affecting midand late-life physical functioning. Genet Epidemiol 2002;23:110-22.

31. Tiainen K, Sipila S, Alen M, et al. Shared genetic and environmental effects on strength and power in older female twins. Med Sci Sports Exerc 2005;37:72-8.

32. Kuh D, Bassey J, Hardy R, et al. Birth weight, childhood size, and muscle strength in adult life: evidence from a birth cohort study. $A m \mathrm{~J}$ Epidemiol 2002;156:627-33.

33. Kuh D, Hardy R, Butterworth S, et al. Developmental origins of midlife physical performance: evidence from a British birth cohort. $\mathrm{Am} \mathrm{J}$ Epidemiol 2006;164:110-21.

34. Kuh D, Bassey EJ, Butterworth S, et al. Grip strength, postural control, and functional leg power in a representative cohort of British men and women: associations with physical activity, health status, and socioeconomic conditions. J Gerontol A Biol Sci Med Sci 2005;60:224-31. 